\title{
Features of Renal Function in Women with Complicated Preeclampsia
}

\author{
IJCRR \\ Section: Healthcare \\ Sci. Journal Impact \\ Factor: 6.1 (2018) \\ ICV: 90.90 (2018)
}

\section{Akhmedov F.K., Negmatullaeva M.N., Tuksanova D.I.}

State Medical Institute Abu Ali 1bn Sina, Department of Obstetrics and Gynecology, Ministry of Health of the Republic of Uzbekistan

\section{ABSTRACT}

Introduction: Study of features of renal function, some indicators homeostasis in women with mild preeclampsia. We have studied 50 women with physiological pregnancy, 100 pregnant women with mild PE (II group) in gestational age 30-34 weeks. The results of the data, it should be emphasized that among the numerous violations of various functions of the body of pregnant women with mild preeclampsia. The most prominent is hypovolemia due to preferential reduction of plasma volume, hypoproteinemia due to proteinuria and reduced renal perfusion parameters with the deterioration of their functional capacity.

Objective: The study of the features of the functional state of the kidneys, some indicators of homeostasis in women during pregnancy complicated by preeclampsia.

Method: We studied 50 women with physiological pregnancy, 100 pregnant women with mild PE (group I), 50 pregnant women with severe PE (group II) at a gestational age of 30-34 weeks. Clinical and laboratory studies were used, including general analysis of blood and urine, fibrinogen, time blood according to Sukharev, a study of the amount of protein in the blood, counting the amount of protein in daily urine and functional methods for assessing the condition of pregnant women.

Result: Assessing the results obtained, it can be indicated that pregnant women with severe preeclampsia have a greater tendency to hypernatremia than pregnant women with mild preeclampsia, which significantly exceeds the concentration of sodium in the plasma of healthy pregnant women. Changes from other electrolytes are not significant.

Conclusion: All this indicates that such a contingent of pregnant women poses a great danger in terms of the occurrence of various complications during pregnancy, childbirth and the postpartum period.

Key Words: Kidney, Renal hemodynamic, Homeostasis, Renal plasma

\section{INTRODUCTION}

Preeclampsia is one of the most common and serious complications in the world of obstetrics, and in recent years a large number of scientific studies have focused on the possibility of preventing this pathology and identifying high-risk groups complicated by preeclampsia. According to the World Health Organization (WHO), preeclampsia is observed in developed countries in 5-15\%, and in developing countries - 30-35\%. Hypertension in pregnant women in different regions of our country is $15-25 \%$. Preeclampsia is one of the main causes of maternal and perinatal death and remains one of the most acute problems of modern medicine. ${ }^{1-3}$

Preeclampsia is one of the main problems in the world leading to pathologies leading to complications during pregnan- cy. PE is an important interdisciplinary problem and occupies a leading position among pathologies that complicate the course of pregnancy. ${ }^{4,5}$ The relevance of studying PE is explained by the high prevalence of this complication, an adverse effect on the course of pregnancy, as well as a risk factor for the mother to develop arterial hypertension, chronic kidney diseases, endocrine disorders, and fatal cardiovascular complications. ${ }^{4-6}$

Nevertheless, based on an analysis of recent scientific studies in several countries (Norway, Ireland, Scotland, Israel), a total of 800,000 pregnancies showed a twofold increase in the risk of death in patients who underwent preeclampsia, especially in preterm birth. ${ }^{2,7}$ Studying the features of renal and systemic hemodynamic during "critical periods of pregnancy" during physiological pregnancy and with the

\section{Corresponding Author:}

Akhmedov F.K., State Medical Institute Abu Ali Ibn Sina, Department of Obstetrics and Gynecology, Ministry of Health of the Republic of Uzbekistan.

ISSN: 2231-2196 (Print) ISSN: 0975-5241 (Online)

Received: $20.09 .2020 \quad$ Revised: 24.10 .2020

Accepted: 22.11 .2020

Published: 05.01 .2021 
development of PE will reveal early diagnostic signs of hypertension that has joined pregnancy. ${ }^{7,8}$

The debatability of several aspects of aetiology and pathogenesis, the heterogeneity and inconsistency of the listed risk factors for PE development, as well as the use of an exclusively anamnestic approach in identifying risk groups for the development of this complication in early pregnancy, emphasizes the need for an in-depth analysis of this problem. ${ }^{1,2,9,10}$

\section{MATERIALS AND METHODS}

Laboratory diagnostics included biochemical studies of renal function and determination of coagulation factors. Evaluation of the excretory function of the kidneys is important both from a clinical and a research point of view. It is known that an increase in serum creatinine, a decrease in creatinine clearance or the estimated glomerular filtration rate (GFR), microalbuminuria are independent prognostic factors of cardiovascular diseases and, in particular, hypertensive syndrome. Accurate direct measurement of GFR is methodologically difficult, therefore, until recently, elevated plasma creatinine levels and special formulas have been widely used in clinical practice. Moreover, their use is not only possible but also does not imply a significant increase in the cost of evaluating kidney function with a definite increase in the accuracy of the study. ${ }^{2-4}$

Cockcroft-Goult Formula (Cockcroft-Goult, FCG),

$\mathrm{GFR}=\{140-$ age $\times$ body mass/ serum creatinine (mg / dl) $\times 72\} \times 0.85$

The study of the renal plasma flow was carried out after a water load (1liter of water drunk for one hour before the study). After the eve of the test, iodine was slowly (3-5 minutes) injected with $3 \mathrm{ml}$ of $70 \%$ triombrost solution. It was established that such a dose of triombrast creates its concentration in the blood within 1-4 mg\% for $40-60$ minutes or more. Women urinated 10 minutes after the end of the introduction of triombrast, and from that time they collected urine for three 15-20 minute intervals by natural urination. In the middle of these gaps, blood was drawn from a vein to determine the concentration of triombrast in it. The study of blood and urinary triombrost was performed by the iodometric method of White, Rolf, using the formula:

$$
\mathrm{DM}=\mathrm{Ic} / \mathrm{Pk} \times \mathrm{V}
$$

Where DM is the coefficient of blood purification from triombrost; Ic - the concentration of triombrast in the urine; $\mathrm{Pk}$ is the concentration of triombrast in plasma; $\mathrm{V}$ - minute diuresis. The calculation of diabetes was carried out for each 15-20-minute period separately. The final result was the numbers of 2-3 periods of the study.

To calculate a renal blood flow was calculated for whole blood based on hematocrit indices using the formula:

\section{Effective renal blood flow $(\mathrm{RBF})=$ renal plasma flow (RPF)/ 1-H (Hematocrit)}

The determination of KF and PP allowed us to calculate the filtration fraction (FF) - the volume of liquid that the plasma gives out during the filtration:

\section{FF(Filtration fraction $)=$ Glomerular filtration rate (GFR) / renal plasma flow (RPF)}

Statistical processing of the results was carried out using Student's test using the Statgraf software package and Microsoft Excel version for Windows.

\section{RESULTS AND DISCUSSION}

A comprehensive study of the functional state of the kidneys and indicators of homeostasis in women during pregnancy with complicated preeclampsia in the period 30 to 34 weeks was carried out.

Many women in this group have a burdened obstetric history (bleeding, placenta previa and placental abruption, intrauterine hypoxia of the fetus, cesarean section).

Pay attention: pallor of the skin, swelling of the lower extremities, abdominal wall and lumbar region. Table No. 1 reflects the indicators of a clinical study of blood and urine in pregnant women of this group, where, for greater clarity, identical indicators of the control group are given (Table 1).

Table 1: Data from a clinical study of blood and urine in women during pregnancy complicated by preeclampsia

\begin{tabular}{|c|c|c|c|c|}
\hline Indicators & $\begin{array}{l}\text { Mild preeclampsia } \\
\qquad(\mathbf{n}=100)\end{array}$ & $\begin{array}{l}\text { Severe preeclampsia } \\
\qquad(\mathbf{n}=\mathbf{5 0})\end{array}$ & Control group $(n=50)$ & $\mathbf{P}$ \\
\hline \multicolumn{5}{|l|}{ Blood } \\
\hline Hemoglobin, g / 1 & $97 \cdot 5 \pm 1.72$ & $74.9 \pm 1.58$ & $101.3 \pm 2.37$ & $<0.01$ \\
\hline Erythrocytes, $10^{12} / 1$ & $3.04 \pm 0.06$ & $2.74 \pm 0.06$ & $3.1 \pm 0.13$ & $<0.01$ \\
\hline $\mathrm{Ht}, \%$ & $36.0 \pm 0.18$ & $25.0 \pm 0.52$ & $36.3 \pm 0.27$ & $<0.001$ \\
\hline Total protein, g / 1 & $69.3 \pm 2.14$ & $62.2 \pm 1.90$ & $81.0 \pm 0.35$ & $<0.001$ \\
\hline
\end{tabular}


Table 1: (Continued)

\begin{tabular}{|c|c|c|c|c|}
\hline Indicators & $\begin{array}{l}\text { Mild preeclampsia } \\
\qquad(\mathbf{n}=\mathbf{1 0 0})\end{array}$ & $\begin{array}{l}\text { Severe preeclampsia } \\
\qquad(\mathbf{n}=\mathbf{5 0})\end{array}$ & Control group $(n=50)$ & $\mathbf{P}$ \\
\hline \multicolumn{5}{|l|}{ Urine } \\
\hline Daily diuresis, ml & $950.7 \pm 27.6$ & $710.6 \pm 16.0$ & $1276.1 \pm 56.8$ & $<0.001$ \\
\hline \multicolumn{5}{|l|}{ Relative density } \\
\hline Maximum & $1.0322 \pm 0.0055$ & $1.0287 \pm 0.0060$ & $1.0242 \pm 0.0086$ & $>0.05$ \\
\hline Minimum & $1.0210 \pm 0.0044$ & $1.0165 \pm 0.0053$ & $1,0104 \pm 0,0086$ & $>0.05$ \\
\hline Protein, g / 1 & $2.57 \pm 0.01$ & $3.45 \pm 0.02$ & $0.46 \pm 0.012$ & $<0.001$ \\
\hline White blood cells & 4-10 & $6-25$ & $2-8$ & \\
\hline
\end{tabular}

The table shows that for pregnant women with hypoproteinemia, proteinuria, a decrease in daily diuresis by almost $44.3 \%$ relative to healthy women at the same stages of pregnancy.

The table shows that women with mild PE are characterized by hypoproteinemia and severe proteinuria. Their total protein content in the blood is $14.4 \%$ lower than in the control group. A decrease in the volume of daily diuresis by $25.5 \%$ was also characteristic, relative to that in women with a normal pregnancy with an increase in the night fraction and a slight decrease in the fluctuation in the relative density of urine. Proteinuria increased by almost $18 \%$.

A study of the functional state of the kidneys showed that during pregnancy with severe preeclampsia, GF decreases to $1.047 \pm 0.048 \mathrm{ml} / \mathrm{s}$, which is $0.704 \mathrm{ml} / \mathrm{s}(34.2 \%),(\mathrm{P}<0.001)$ lower than the GF of pregnant control groups and lower than in pregnant women with severe preeclampsia $(\mathrm{P}<0.001)$, respectively, $0.020 \mathrm{ml} / \mathrm{s}(1.9 \%)$.
Tubular reabsorption, amounting to $98.4 \pm 0.5 \%$, as in the severe preeclampsia group, was reduced relative to the same indicator of the control group by only $0.3 \%(\mathrm{P}>0.05)$.

A decrease in GF was combined with a violation of the concentration function of the kidneys in women of this group. The concentration of urea and creatinine in the blood, averaging $5.8 \pm 0.6 \mathrm{mmol} / 1$ and $123.7 \pm 1.4 \mathrm{mmol} / 1$, was higher than the control values by $30.9 \%$, respectively $(\mathrm{P}<0.05)$ and $77.2 \%(\mathrm{P}<0.05)$ and higher than in the group with mild preeclampsia by $28.4 \%(\mathrm{P}>0.005)$.

In this study group, the increase in creatinine significantly exceeded the growth of urea in the blood and was already above the upper limit of physiological values. The lag of urea growth in pregnant women with severe PE is possibly associated with a decrease in urea with the synthesis ability of the liver.

Table 2: Biochemical blood parameters in women during pregnancy complicated by preeclampsia.

\begin{tabular}{|c|c|c|c|c|}
\hline Indicators & $\begin{array}{l}\text { Mild preeclampsia } \\
\qquad(\mathbf{n}=100)\end{array}$ & $\begin{array}{c}\text { Severe preeclampsia (n } \\
=\mathbf{5 0})\end{array}$ & Control group $(n=50)$ & $\mathbf{P}$ \\
\hline \multicolumn{5}{|l|}{ Plasma electrolytes, mol / 1} \\
\hline Plasma sodium, mol / L & $137.7 \pm 2.51$ & $139.1 \pm 2.47$ & $130.5 \pm 3.20$ & $<0.05$ \\
\hline Potassium plasma, mol / L & $3.7 \pm 0.06$ & $3.4 \pm 0.05$ & $3.6 \pm 0.03$ & $<0.001$ \\
\hline Plasma calcium, mol / 1 & $1.90 \pm 0.034$ & $2.1 \pm 0.04$ & $2.45 \pm 0.02$ & $<0.001$ \\
\hline Urea, ml mol / L & $5.67 \pm 0.09$ & $5.8 \pm 0.11$ & $4.4 \pm 0.04$ & $<0.001$ \\
\hline Creatinine, $\mu \mathrm{mol} / \mathrm{L}$ & $96.3 \pm 1.81$ & $123.7 \pm 2.08$ & $69.8 \pm 2.10$ & $<0.001$ \\
\hline
\end{tabular}

The above table reflects the nature of changes related to blood electrolytes in pregnant women with severe preeclampsia (for comparison, we give the data of the control group).

Assessing the results obtained, it can be indicated that pregnant women with severe preeclampsia have a greater tendency to hypernatremia than pregnant women with mild preeclampsia, which significantly exceeds the concentration of sodium in the plasma of healthy pregnant women. Changes from other electrolytes are not significant.

The study of clearance and excretion of electrolytes by the kidneys with severe preeclampsia showed that these indicators are very similar to the data of clearance and excretion of electrolytes with mild preeclampsia. For clarity, we have reduced them to a table. 
Table 3: Clearance and excretion of electrolytes by the kidneys during pregnancy complicated by preeclampsia

\begin{tabular}{|c|c|c|c|c|}
\hline Indicators & $\begin{array}{l}\text { Mild preeclampsia (n } \\
=100)\end{array}$ & $\begin{array}{l}\text { Severe preeclampsia } \\
\qquad(\mathbf{n}=\mathbf{5 0})\end{array}$ & Control group $(n=50)$ & $\mathbf{P}$ \\
\hline \multicolumn{5}{|c|}{ Clearance, $\mathrm{ml} / \mathrm{min}$} \\
\hline Sodium & $0.69 \pm 0.02$ & $0.62 \pm 0.02$ & $0.73 \pm 0.023$ & $>0.05$ \\
\hline Potassium & $7.11 \pm 0.23$ & $5 \cdot 44 \pm 0.16$ & $8.91 \pm 0.34$ & $<0.001$ \\
\hline Calcium & $1.34 \pm 0.04$ & $1.28 \pm 0.04$ & $1.61 \pm 0.14$ & $>0.05$ \\
\hline \multicolumn{5}{|l|}{ Excretion,\% } \\
\hline Sodium & $0.68 \pm 0.03$ & $0.70 \pm 0.02$ & $1.04 \pm 0.031$ & $<0.001$ \\
\hline Potassium & $8.14 \pm 0.27$ & $6.82 \pm 0.21$ & $11.1 \pm 0.37$ & $<0.001$ \\
\hline Calcium & $1.19 \pm 0.04$ & $0.87 \pm 0.03$ & $2.04 \pm 0.066$ & $<0.001$ \\
\hline
\end{tabular}

The table shows that with severe preeclampsia of all the studied electrolytes, the most significant was a decrease in sodium excretion, which amounted to $34.6 \%$ relative to healthy pregnant women, causing hyperhydration.
In contrast to sodium, both clearance and potassium excretion, despite the stated hypokalemia in these women, remain relatively high, which can adversely affect neuromuscular conduction in general, including in myometrium during childbirth.

Table 4: Indicators of renal hemodynamic in women during pregnancy complicated by preeclampsia

\begin{tabular}{|c|c|c|c|c|}
\hline Indicators & $\begin{array}{l}\text { Mild preeclampsia } \\
\qquad(\mathbf{n}=100)\end{array}$ & $\begin{array}{l}\text { Severe preeclampsia } \\
\qquad(\mathbf{n}=\mathbf{5 0})\end{array}$ & $\begin{array}{l}\text { Control group } \\
\qquad(n=50)\end{array}$ & $\mathbf{P}$ \\
\hline Renal plasma flow, $\mathrm{ml} / \mathrm{min}$ & $391.7 \pm 6.9$ & $404.2 \pm 7 \cdot 4$ & $554 \cdot 7 \pm 18.6$ & $<0.001$ \\
\hline Effective renal blood flow, $\mathrm{ml} / \mathrm{min}$ & $620.7 \pm 10.8$ & $539.6 \pm 9.6$ & $767.8 \pm 26.1$ & $<0.001$ \\
\hline Filtration fraction & $0.16 \pm 0.003$ & $0.15 \pm 0.003$ & $0.19 \pm 0.007$ & $<0.001$ \\
\hline
\end{tabular}

In this group, the lowest renal plasma, effective renal blood flow and filtration fraction were noted, which corresponds to the degree of impaired renal functional ability.

\section{DISCUSSION}

In women with severe preeclampsia, the lowest (relative to the previous groups) effective renal blood flow was registered, which turned out to be lower than the control values by $37.0 \%$, while the renal plasma flow was underestimated by $26.0 \%$. A decrease in kidney perfusion in pregnant women with a similar form of severe preeclampsia is understandable from the standpoint of the hypovolemia that occurs in them.

Hypovolemia, worsening renal blood and plasma, could not but affect the functional state of the kidneys in pregnant women of this group. Statistically significantly decreased GF by $59.7 \%$ relative to the same indicator in the pregnant control group. All this affected the amount of daily urine output, which turned out to be the lowest relative to all previous groups and was $44.4 \%$ lower than that of healthy women in the same period of pregnancy.

In pregnant women of this group, a marked violation of the concentration function of the kidneys is noted. Urea and creatinine were the highest among the examined groups. An interesting difference was the growth in urea and creatinine. So, if blood urea in this group of pregnant women was higher than the control values by $32.9 \%$, then their creatinine increased by $75.7 \%$, which may indirectly indicate a violation of the liver functions. Reduced clearance and especially sodium excretion creates the prerequisites for its delay in the body of such a contingent of pregnant women.

\section{CONCLUSION}

Summarizing the changes taking place on the part of the studied parameters in women with severe preeclampsia, it can be noted that they are characterized by hypoproteinemia, proteinuria, and a decrease in daily diuresis, the severity of which exceeds all other studied groups of pregnant women. Marked hypovolemia, extracellular hyperhydration, a tendency to myocardial hypodynamia, deterioration of renal hemodynamic with a decrease in FF and renal functional ability in women of this group are most pronounced. All this indicates that such a contingent of pregnant women poses a great danger in terms of the occurrence of various complications during pregnancy, childbirth and the postpartum period. Such pregnant women approach childbirth, having 
almost exhausted all their reserve capabilities. One of the weakest links in the general chain of occurring disorders in women with severe preeclampsia is the kidneys.

\section{Conflict of Interest: None}

\section{Source of Funding: None}

\section{REFERENCES}

1. Vasiliev V, Tyagunova AV, Drozheva VV. Renal function and indicators of endogenous intoxication with gestosis. Obstet Gynaec 2013; 4:16-20.

2. Ivanova OI; Ponomareva MG; Gazazyan ZL. Features of central hemodynamics during pregnancy complicated by gestosis. J Obstet Female Dis 2008;7(3)4-9.

3. Alper AB, Yi Y, Weber LS.Estimation of glomerular filtration rate in preeclamptic patients. Am J Perinatol 2007;24:569.

4. Alieva TM, Abdukarimov TA. Preeclampsia factors, prerequisites, climatogeographic features. News Dermatol Reprod Health 2016; 4;50-54.
5. Akhmedov F.K. Features of renal function and some indicators of homeostasis in women with mild preeclampsia. Eur Sci Rev 2015;4(5):58-60.

6. Akhmedov FK, Avakov VE, Negmatullaeva MN. Status of cardio-hemodynamics and cardiac geomerms in women with complications with severe preeclampsia. News Dermatol Reprod Health Tashkent 2017;3(I):27-29.

7. Buchbinder A, Sibai B, Caritis S. Adverse perinatal outcomes are significantly higher in severe gestational hypertension than in mild preeclampsia. Am J Obstet Gynec 2002; 186(1):66-71.

8. Nishanova FP, Mustafayeva ME. Maternal mortality from preeclampsia in the Republic of Uzbekistan. Physician Bull 2009; 2:78-81.

9. Guryeva MV, Yu B, Kotov VA. Daily monitoring of blood pressure and heart rate in the diagnosis. Russ Bull Obstet Gynec 2013;3: 4-9.

10. Makarova OV, Nikolaev NN, Volkova EV. Features of central hemodynamics in pregnant women with arterial hypertension. Obstet Gynec 2003; 4:18-22 . 